\title{
Implementing invasive species management in an adaptive management framework
}

\author{
Authors: \\ Llewellyn C. Foxcroft ${ }^{1,2}$ \\ Melodie McGeoch ${ }^{2,3}$ \\ Affiliations: \\ ${ }^{1}$ South African National \\ Parks, Conservation Services, \\ Skukuza, South Africa \\ ${ }^{2}$ Centre for Invasion Biology, \\ Stellenbosch University, \\ South Africa \\ ${ }^{3}$ South African National \\ Parks, Cape Research Centre, \\ Cape Town, South Africa \\ Correspondence to: \\ Llewellyn Foxcroft \\ Email: \\ llewellyn.foxcroft@sanparks. \\ org \\ Postal address: \\ Private Bag X402, Skukuza \\ 1350 , South Africa \\ Dates: \\ Received: 31 May 2010 \\ Accepted: 14 Jan. 2011 \\ Published: 13 May 2011 \\ How to cite this article: \\ Foxcroft, L.C. \& McGeoch, \\ M., 2011, 'Implementing \\ invasive species management \\ in an adaptive management \\ framework', Koedoe 53(2), \\ Art. \#1006, 11 pages. \\ doi:10.4102/koedoe. \\ v53i2.1006
}

(C) 2011. The Authors. Licensee: OpenJournals Publishing. This work is licensed under the Creative Commons Attribution License.
Adaptive management theory has attracted substantial interest in recent years, in natural resource management in general and also for invasive alien species management. However, whilst many theoretical and conceptual advances have been made, documented cases of practical applications are rare. Coupling invasive species management components with adaptive feedback processes is not without challenges, requiring a substantial change in the thinking and practice of all those involved. Drawing on a decade of experience in South African National Parks, we suggest an approach to implementing adaptive management for controlling invasive alien species. Whilst efforts have been made to advance components of the overall management strategy, the absence of a framework for decision making and feedback mechanisms, inflexibility in the system and shortcomings in the governance structure are all identified as barriers to learning and knowledge integration for the purposes of effective invasive alien species management. The framework provided here, encompassing documents, committees and processes, is aimed at addressing these shortcomings.

Conservation implication: Adaptive management theory offers a robust tool for managing inherently complex systems. Its practical application, however, requires distilling the theory into useable functions. We offer a framework to advance implementation of strategic adaptive management for the control of invasive alien species using experiences gained from South African National Parks.

\section{Introduction}

Ecosystems are dynamic, changing in both space and time and over multiple scales (Pickett, Cadenasso \& Benning 2003). These fluctuations are both necessary and desirable. Adaptive management (AM) has emerged as a preferred method of management for natural resources in the face of such change and inherent uncertainty (Biggs \& Rogers 2003; Gregory, Ohlson \& Arvai 2006; Jacobson et al. 2006; Salafsky, Margoluis \& Redford 2001; Scholes \& Kruger 2011). Accordingly, South African National Parks (SANParks) has adopted the principles of AM to guide decision making (Rogers 2003). AM generally includes the following steps: (1) developing a conceptual understanding of the social-ecological system, (2) developing objectives and management plans, (3) implementing management, (4) monitoring trends and system changes, (5) analysing data, and (6) purposefully modifying management in response to outcomes where necessary (e.g. Salafsky et al. 2001). Strategic adaptive management (SAM), as applied in SANParks, encompasses the general AM process, but differs by focussing more explicitly on (1) developing a mutual understanding and appreciation by stakeholders of the way ecosystem goods and services are valued, (2) building an understanding of the social, technological, economic, environmental and political context and (3) establishing an adaptive assessment process for defining spatially and temporally explicit monitoring programmes that assess the response of ecosystems to management actions (Biggs \& Rogers 2003; Roux \& Foxcroft 2011). The focus on these aspects is an attempt to overcome some of the barriers (communication, attitudinal and conceptual) to AM implementation (Jacobson et al. 2006).

A further contribution that SANParks has made to AM theory has been the development of thresholds of potential concern (TPCs) (Roux \& Foxcroft 2011). Based on best available science and updated as new understanding emerges, TPCs allow for some measure of system flux whilst highlighting points in a trend that reflect unacceptable environmental consequences and therefore require management interventions. As shown in Figure 1, a three-dimensional space represents possible changes in the system attribute of interest over time and space. The sphere represents the outer boundaries of the desirable system, which are represented by TPCs. Any directional change in the system within the boundaries (or TPCs) is considered acceptable - even desirable ecosystem flux (blue to green arrow). Should the system be outside or on a trajectory leading out of the desired set of conditions (blue or green to orange arrow) - a TPC thus having been breached - an assessment of the cause of the system change and possible management interventions are called for. For alien species, TPCs are breached when new alien species are introduced or 
species already in the system spread (red arrow). These thresholds are low because once highly invasive species have established, they are likely to spread over a wide area, with long-lasting impacts on the system attribute of interest (e.g. plant diversity in riparian areas).

The use of TPCs creates an opportunity to implement management strategies as landscape scale experiments, from which the outcomes of the management interventions must necessarily be assessed. TPCs also represent another difference between general AM approaches and SAM as applied in SANParks, in that TPCs aim to pre-empt impending unacceptable system change and thus allow for proactive management options (Scholes \& Kruger 2011). Long-term monitoring aims to detect these trends and changes in various ecological features (Buckley et al. 2008) and is therefore an essential component in the implementation of AM (Rogers 2003). The outcome of monitoring and analysis is measured against predefined indicators and associated TPCs (Biggs \& Rogers 2003). This assessment provides feedback on the outcomes of management actions and, in the process, provides both a formal and an informal means of learning and knowledge diffusion (Biggs \& Rogers 2003).

Most ecosystems in South Africa have been invaded by a large number of taxonomic groups (Richardson et al. 2000), resulting in a wide range of negative impacts on biodiversity and social-economic systems (Pyšek \& Richardson 2010). The most well-documented, ecologically harmful taxa are plants, many of which are woody plants (Richardson, Rouget \& Rejmánek 2004). Although conservation areas are protected from some threats (e.g. large-scale habitat transformation or over-exploitation of resources), other threats are more difficult to exclude (Kareiva et al. 2007; Millennium Ecosystem Assessment 2005; Woodroffe \& Ginsburg 1998). Globally, invasive alien species are a substantial and escalating threat to the integrity of many

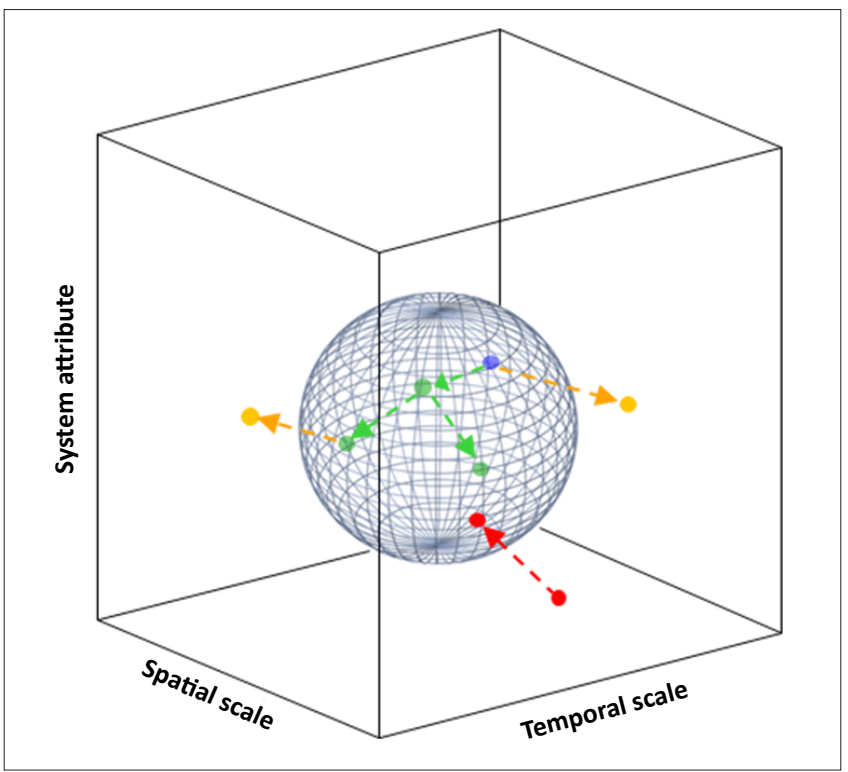

FIGURE 1: The threshold of potential concern may be represented as a threedimensional space, showing possible changes in the system attribute of interest over time and space. ecosystems within protected areas (MEA 2005). This can be attributed, in part, to the fact that protected areas often exist as islands in a sea of diverse, human-dominated land uses (Pickett \& Thompson 1978), where disturbances and propagule sources are strong drivers of biological invasions (Hobbs \& Huenneke 1992). For example, the Kruger National Park (KNP), with an area of approximately $20000 \mathrm{~km}^{2}$, has been invaded by about 370 alien plants; 27000 plant records having been collected (Foxcroft et al. 2009). KNP also has a history of alien species management policies based either on national legislation (initially the Conservation of Agricultural Resources Act; Act 43 of 1983, and later amendments in 2001) or on the internal needs of the park (e.g. a policy on the use and management of alien ornamental plants as described by Foxcroft [2001] and Foxcroft and Freitag-Ronaldson [2007]). More recently, the development of the National Environmental Management: Biodiversity Act (Act 10 of 2004) and the National Environmental Management: Protected Areas Act (Act 57 of 2003) has determined the legislative context within which all management and monitoring must take place, including those for invasive alien species. This, together with the experience gained in SANParks (and KNP) over the last decade in applying SAM to invasive alien species (Bestbier, Jacoby \& Rogers 2000; Foxcroft \& Richardson 2003; Foxcroft \& Downey 2008; Foxcroft 2009), provides a useful platform for proposing future management options. However, three key shortcomings are considered to exist in the current approaches to management of invasive alien species in SANParks. These are forms of institutional barriers to the implementation of AM (Jacobson et al. 2006) and include (1) the lack of a broad framework for decision making, (2) the inflexibility in existing management systems and administration and (3) shortcomings in the governance structure for invasive alien species management.

\section{Need for an invasive alien species policy and management framework}

Although frameworks for implementing SAM for alien species management have been proposed (Bestbier et al. 2000; Freitag-Ronaldson \& Foxcroft 2003), emphasis has been largely on developing specific TPCs to date. Since 1999, 37 cases of breached thresholds have been documented (supplementary material (Table 2) in Foxcroft [2009]). In some cases the lack of clarity of departmental responsibility for responding to the breached TPC led to confusion, delaying management action. Thus, although the thresholds were designed to trigger appropriate interventions (mainly rapid eradication or containment strategies as described by Foxcroft [2009]), the lack of an overall policy and management framework within which they could operate impeded a coordinated response. Moreover, although the TPCs include monitoring for new incursions of alien species into parks, almost all attention has been on control, with little focus on prevention. Although this is a global trend (Keller \& Lodge 2010), a substantial increase in focus on prevention is essential if parks are to manage invasive alien species successfully in the long term. 
In a large natural system such as the KNP, where many alien species have been introduced (Foxcroft et al. 2003), not all species can or necessarily need to be managed. Some alien species will also experience fluctuations in their population density and spatial distribution over time, although the most invasive and potentially damaging species will tend to become, and remain, highly abundant and widespread (Freitag-Ronaldson \& Foxcroft 2003:414). It is these 'transformer' species that alter the landscape over a wide area, often in both structure and function (Pyšek et al. 2004), that are of most concern and thus the focus of management attention. Without an overarching framework and coordinated effort to identify where and when TPCs are required (e.g. Tu 2009), and to respond when they are breached, efforts will remain largely opportunistic and potentially ineffective (Hall \& Fleishman 2009).

Another aspect that requires further consideration is adaptive governance, which is the process by which social systems are organised or reorganise themselves (Folke et al. 2005). Governance provides the structures and processes needed in which collective decisions are taken. Adaptive governance networks join teams that contain different experiences to develop a common understanding of management and policies. The governance networks function across multiple levels within organisations, between organisations and between individuals (Folke et al. 2005). These networks provide for enhanced flexibility (a requisite for rapid response to invasions), but still operate within the organisational hierarchy, holding specific agencies, management levels or individuals accountable for inaction or mismanagement. In discussing biosecurity risks of invasive alien species in Australia, Cook et al. (2010:1308) discuss governance structures for interagency cooperation to improve information transfer for surveillance, response, diagnostics, risk analysis and border inspections. These functions are carried out by a number of organisations in a number of different ways. Similarly, we suggest that greater focus on the governance structure of invasive alien species management is required for improved utility of the framework we present. An organisational policy for alien and invasive species management will, for example, contribute significantly to the governance of management of invasive alien species in SANParks.

\section{Need for flexibility and rapid response for management of invasive alien species}

Globally, management of invasive alien species has developed in a number of forms, including risk assessment, vector and pathway control, early detection and rapid response (Pyšek \& Richardson 2010). Although eradication is touted as the main aim of control, containment and maintenance of target populations at low levels are often the only feasible option (Rejmánek \& Pitcairn 2002), particularly with transformer species. As part of a containment strategy, best management practices include setting fixed goals, delineating fixed areas, listing priority species for control, applying available resources to these areas, and follow- up operations, all of which are commonly planned on an annual time scale (eds. Wittenberg \& Cock 2001). These are all an essential part of the overall planning process, but the associated rigidity does not always allow for the surprises that are common features in dynamic ecological systems. Examples of such unforeseen events include large, infrequent disturbances, such as floods and fires. In response to these disturbance events, invasive species that were previously being maintained at a low abundance or contained within a small area may re-emerge rapidly and over a large area after a long period of apparent stability (e.g. Crooks 2005). The events given in these examples are likely to cause the TPCs to be exceeded, requiring immediate assessment and action rather than reliance on a set of fixed medium-term or longterm goals. Moreover, such events may necessitate complete reorganisation of control projects, either to take advantage of a particular situation or to mitigate undesirable changes. This process requires reassessing the order of planned control actions, revising priorities and redirecting resources, often at relatively short notice. In large bureaucracies this is a time-consuming process, which is likely to delay or prohibit opportunities for eradication or early containment.

Consistent long-term management and control of invasive alien species is essential. Should follow-up operations cease, all the resources used and advances achieved in clearing a particular area may be lost in a very short time. We suggest here that an additional layer of planned management action, designed for and focussed on enabling rapid response to unexpected changes, should be implemented. Successful management of invasive alien species necessarily includes effective rapid response along with consistent clearing and follow-up operations. We also aim here to place these actions, together with those already in practice, in their broader framework and context. Whilst management action in SANParks has to date been virtually aimed exclusively at invasive alien plants, the proposal outlined here is generally relevant to other alien taxa.

\section{Constructing the foundations: Developments to date}

SANParks has invested substantially in adopting and further developing AM principles and a number of unique constructs have been instituted. Notably, these include a hierarchy of objectives (cascading down from the organisational vision to ground level or individual goals) to structure park management priorities and the use of decision thresholds. Although a number of management functions are in place, albeit in varying stages of development, they have largely functioned in isolation of one another to date. These components include:

- the SANParks vision and individual park mission statements

- park management plans, comprising the park-specific objectives

- lower level plans (LLPs), which are specific operational plans for all management concerns in a park; the LLPs 
stem from the park management plan objectives and are written, for example, for fire management, invasive alien species management, artificial water provision, rehabilitation and many other aspects of protected area management

- management unit clearing plan (MUCP) and annual plan of operation (APO); these documents are mediumterm to short-term plans used by the SANParks Invasive Species Control Unit (ISCU) to prepare and guide project implementation and independent contractor management

- physical implementation of control programmes for invasive alien species by ISCU and/or park management

- indicators and TPCs, which, for the purposes of invasive alien species management, have largely been decision thresholds (i.e. mTPCs as in Foxcroft [2009]), indicating points at which management decisions and intervention are usually required; these have only been used in a few parks to date

- fora where selected invasive alien species management issues are discussed intermittently; however, in most cases this dialogue has taken place informally between park managers or rangers and the ISCU project managers, but needs to be complemented by more formal discourse

- functional feedback loops, which are inherent in AM processes (Stafford-Smith et al. 2009) and are aimed at enhancing understanding and ensuring continuous improvement in management effectiveness.

Together, the listed objectives, plans, interactions and processes should complement one another in the functions they perform, and thus form a foundation for consolidating effective management of alien and invasive species. The relative roles of these management functions and the relationships between them should also be clear. However, a number of gaps remain and further components are necessary, such as a coordinated monitoring programme to enhance the optimal implementation of an overall response to invasive alien species management and efficient feedback mechanisms. Here we identify these gaps and suggest ways to address them and also clarify the relative roles and relationships between each of the management functions. Finally, we suggest how the various components may be integrated into an overall SAM framework for invasive alien species management.

\section{A framework for advancing adaptive management of invasive alien species}

Conceptual frameworks are tools to organise and evaluate the state of a particular system (Pickett, Kolasa \& Jones 2007). A framework provides a way of deriving a common understanding of a system or process, whilst also indicating various levels of feedback and learning (Tu 2009).

The schematic diagrams we use to illustrate the framework that is required for an overall, coordinated approach to managing invasive alien species (Figures 2 and 3) are embedded within the overarching SAM paradigm in use by SANParks. We suggest specific components in the framework and illustrate explicit pathways between these components. We further provide a detailed description of each aspect of the management cycle, highlighting their key attributes. The number shown in parentheses at each subsection in the ensuing discussion relates to the numbered boxes in Figures 2 and 3. Although a broader context informs the development of each step (e.g. deriving vision statements and vital attributes at the organisational or park scale [Biggs \& Rogers 2003]), we assume these processes have taken place and frame our discussion in the more focussed context of management of invasive alien species.

\section{SANParks vision and mission statements (1)}

The SANParks vision and mission statements provide the overall direction that guides all decision making. This cascades down to park level, where the vital attributes of the park steer local decision making. For example, the main focus of Mapungubwe National Park as a World Heritage Site is based on its rich cultural heritage (South African National Parks 2006). The KNP is a representative of a relatively intact large savanna ecosystem, with various processes and species that interact over large spaces and long time frames (Pickett et al. 2003), whilst Table Mountain National Park supports a significant portion of rare and endemic taxa forming part of the globally renowned Cape Floristic Region (Cowling et al. 2003). These attributes guide the management focus of each park.

\section{Park management plan (2)}

The park management plan, a legislative requirement in South Africa for all protected areas (National Environmental Management: Protected Areas Act), provides park-specific context and guides actions. The components of the park management plans are hierarchical (e.g. Biggs \& Rogers 2003:63) and are sequentially split into themes, which are then expanded upon in LLPs. In the context of invasive alien species, the LLP presents a risk assessment of species that present the greatest threat or concern, the planned management interventions, financial and resource-related requirements, monitoring, and research needs. Therefore the LLP essentially forms the roadmap for managing invasive alien plants in a park over a five-year cycle. The LLP is, in turn, translated into an MUCP (a five-year plan that runs concurrently with the LLP) and from there to an APO. The APO provides details of each work area to be contracted out for clearing, specific details of the areas to be cleared (with maps), species lists and information about species abundance, human resources, control methods and other project-specific details.

\section{Management forum (3)}

A forum for each park (commonly referred to as a sciencemanagement forum), should be the nexus for integrating all components of the invasive alien species management cycle. This forum includes park managers, staff of the ISCU, project 


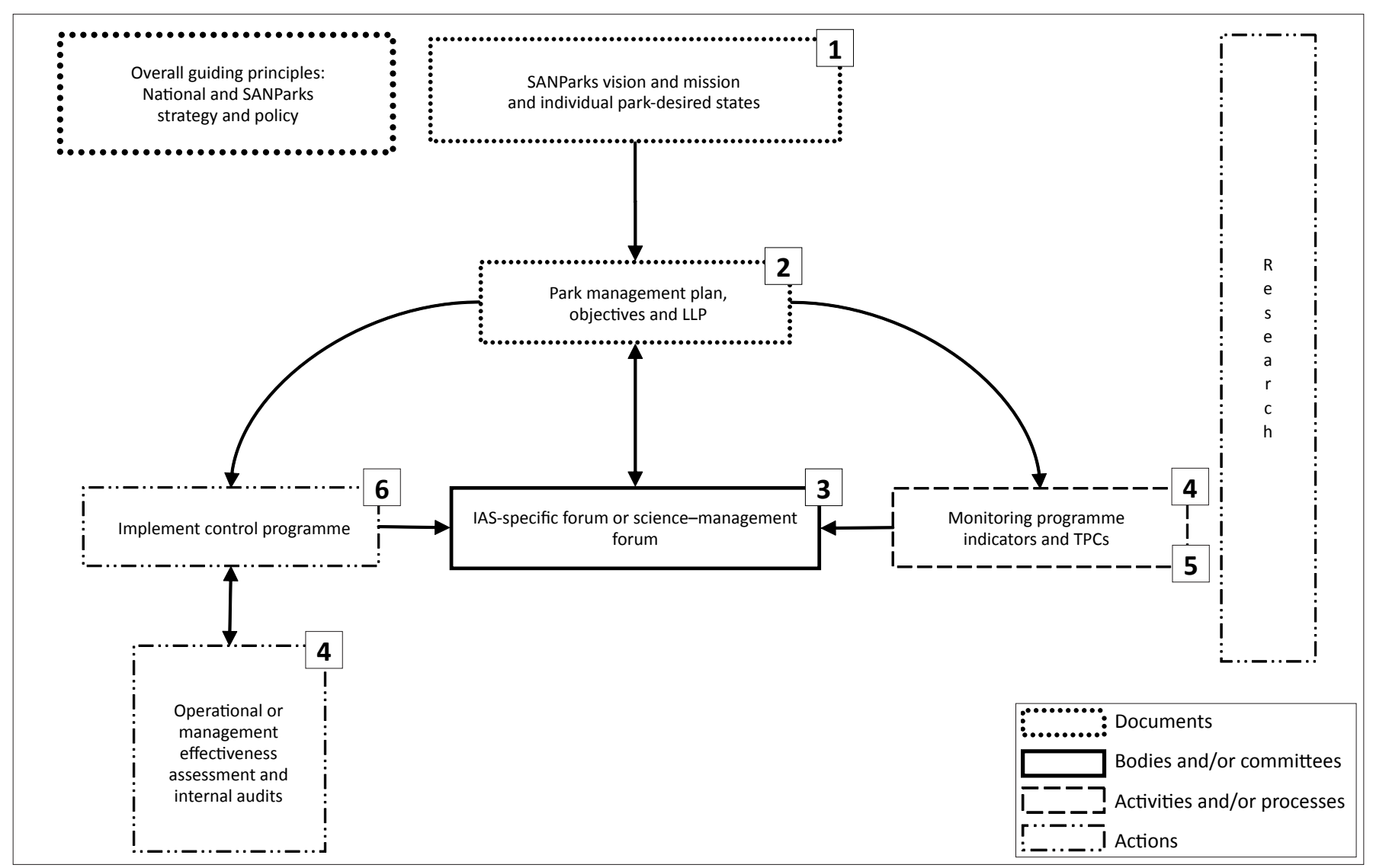

LLP, lower level plans; IAS, invasive alien species; TPC, threshold of potential concern.

FIGURE 2: An overview of the adaptive management process for an overall invasive alien species management framework. Each number in the figure is related to the specific point in the ensuing discussion. The monitoring programme (number 4 ) is further expanded on in Figure 3.

managers and regional ecologists and also receives input from specialist researchers where needed. The development of the park plans, specifically the LLPs and APOs, should be formulated by this group - a process which has happened very rarely. Ideally, these fora should take place at least biannually to reassess progress and revise plans, thereby providing feedback to all. The proposed planning process would contribute to achieving a common understanding of the overall invasive alien species control programme. Moreover, experience of all role players and short-term internal feedback loops between park managers, ISCU project managers and the regional ecologists, are essential for adapting and improving operational plans to increase their flexibility and effectiveness.

\section{Monitoring (4)}

Monitoring is the cornerstone on which all forms of AM rest (Salafsky et al. 2002). This is because AM requires implementing management actions as experiments. As a consequence, monitoring is needed to determine how the system responds to management (Biggs \& Rogers 2003). The term 'monitoring' is not used consistently, leading to subsequent confusion about applying monitoring methods in a particular situation (see Dewey \& Anderson 2004). We differentiate between the following:

1. monitoring long-term trends in the ecosystem as a response to management interventions
2. assessing operational or management effectiveness

3. project auditing (Stem et al. 2005).

\section{Long-term trends in ecosystem change}

Such monitoring assesses the ecological outcome of management efforts. Here we refer to monitoring as the 'collection and analysis of repeated observations or measurements to evaluate changes in condition and progress toward meeting a management objective' (Elzinga et al. 2001). The main objective of the SANParks monitoring programme for alien and invasive species is to assess the status of and trends in invasion, distribution and management of alien species in SANParks, such that the information contributes to management and policy development at a local as well as global level. The approach forms part of the SANParks Biodiversity Monitoring System (McGeoch et al. 2011). In order to achieve this higher objective, three subobjectives are proposed as outlined in the following:

- Subobjective 1: To determine and monitor the rate of introduction of all alien species into the SANParks estate. The main target of this objective is to prevent the introduction of any new invasive alien species into a park.

- Subobjective 2: To determine and monitor the distribution of existing naturalised and invasive species within and across parks. The target of this objective is to contain the spread of invasive species that are already present.

- Subobjective 3: To determine and monitor the increase 
in the abundance and distribution of naturalised and invasive alien species in parks (with distribution used as a predictor and proxy for abundance, as proposed by He and Gaston [2000]). The target of this objective is to maintain the abundance of invasive species below an acceptable threshold.

\section{Operational management effectiveness}

Monitoring aims to provide rapid feedback on control activities that will allow project managers to assess progress and strategically adapt their plans as necessary. Owing to the vast areas being controlled across the SANParks estate, this will most likely have to be a rapid assessment of a few randomly selected sites (see Stem et al. 2005). Within a management unit, data may be collected on, for example, whether a target species has been cleared, whether plants have been missed, are coppicing (resprouting), and whether there have been any negative impacts on nontarget species. In addition, distribution data should be collected opportunistically for any newly observed species or an increase in the distribution of a listed species.

\section{Project auditing}

In this case monitoring aims to assess the implementation of the project and procedures (Stem et al. 2005). These include logistic arrangements, contractor implementation and contractual obligations, occupational health and safety compliance, compliance with herbicide use policies and other aspects which directly relate to the smooth implementation of projects. Many of these components are legislative requirements and need to be performed according to a fixed schedule.

\section{Indicators and thresholds (5)}

TPCs have long been under development and refinement in the KNP (Biggs \& Rogers 2003) and more recently also in other parks. Foxcroft (2009) provides the theoretical background to the current suite of TPCs for invasive alien species. The use of indicators and their associated TPCs provide endpoints against which monitoring of the response of an ecosystem to management intervention may be assessed. In other words, indicators are dependent variables (e.g. the number of alien species or area of a park invaded by invasive alien species), whereas a TPC is the specific value(s) of that indicator for which well-considered intervention is needed (e.g. the introduction of one new alien species to a park or a $10 \%$ increase in the area invaded). The indicators should be assessed according to a 3-5-year time frame and any thresholds which have been breached at this point should be raised at the relevant park forum (Figure 3). If a TPC has been breached at any other time, it should also be documented and presented at the appropriate science-management forum. In this way any unacceptable trends that suggest potential deleterious ecological or biodiversity consequences are given specific attention.

Using TPCs as a reference point for management interventions does not imply that ongoing control operations are stopped and initiated only when a TPC is breached. Rather, parallel to ongoing control operations, TPCs are used to highlight the threshold in a trend where undesirable impacts are expected (Foxcroft 2009) and where additional control, or reorganising and reprioritising, of projects is required. Management actions should, therefore, aim to prevent the system from reaching such thresholds. Where a TPC is breached, the background, cause of concern, potential impacts or consequences and proposed management actions should be discussed. Although TPCs represent hypotheses that are open to challenge, testing and refinement at any time, the validity of the TPC should not be challenged once a breach of a TPC has been tabled (Biggs \& Rogers 2003). This is to prevent 'management paralysis', where the threshold or indicator is continuously questioned and further assessments and research are called for, instead of decisive management action being taken (Biggs \& Rogers 2003).

\section{Invasive alien species management programmes (6)}

In SANParks, the ISCU is largely responsible for the implementation of invasive alien species management programmes, although park managers, rangers, regional ecologists and scientists are all required to provide input at various stages. The ISCU operations are largely funded by the national Working for Water programme (see Van Wilgen, Le Maitre and Cowling [1998] and Van Wilgen, Khan and Marais [2010] for a discussion on the Working for Water programme), with SANParks providing management, financial, logistic and other support.

\section{Multiple feedback processes (7)}

One of the key features of all forms of AM is multiple feedback loops between stages (Biggs \& Rogers 2003; Maris \& Béchet 2010; Stafford-Smith et al. 2009). Continuous evaluation and self-assessment of all stages of the management process provide information on the outcome of previous interventions and allow for ongoing improvement (Timko \& Innes 2009). Further, purposeful reflection and assessment provide growing understanding of the desired management goal and progress impediment (Venter et al. 2008).

Purposeful learning and continuous feedback between the various players involved in management of invasive alien species in SANParks have largely been absent to date, despite substantial efforts to enhance communication. We suggest that the schematic frameworks presented here outline a governance structure and provide clear linkages to assist role players in visualising the contribution of all components of invasive alien species management and the feedbacks required amongst them.

\section{Conclusion}

Institutionalising changes to an existing management paradigm is not without challenges. The framework we illustrated aims to combine and integrate management functions that are already in place or are being developed. 


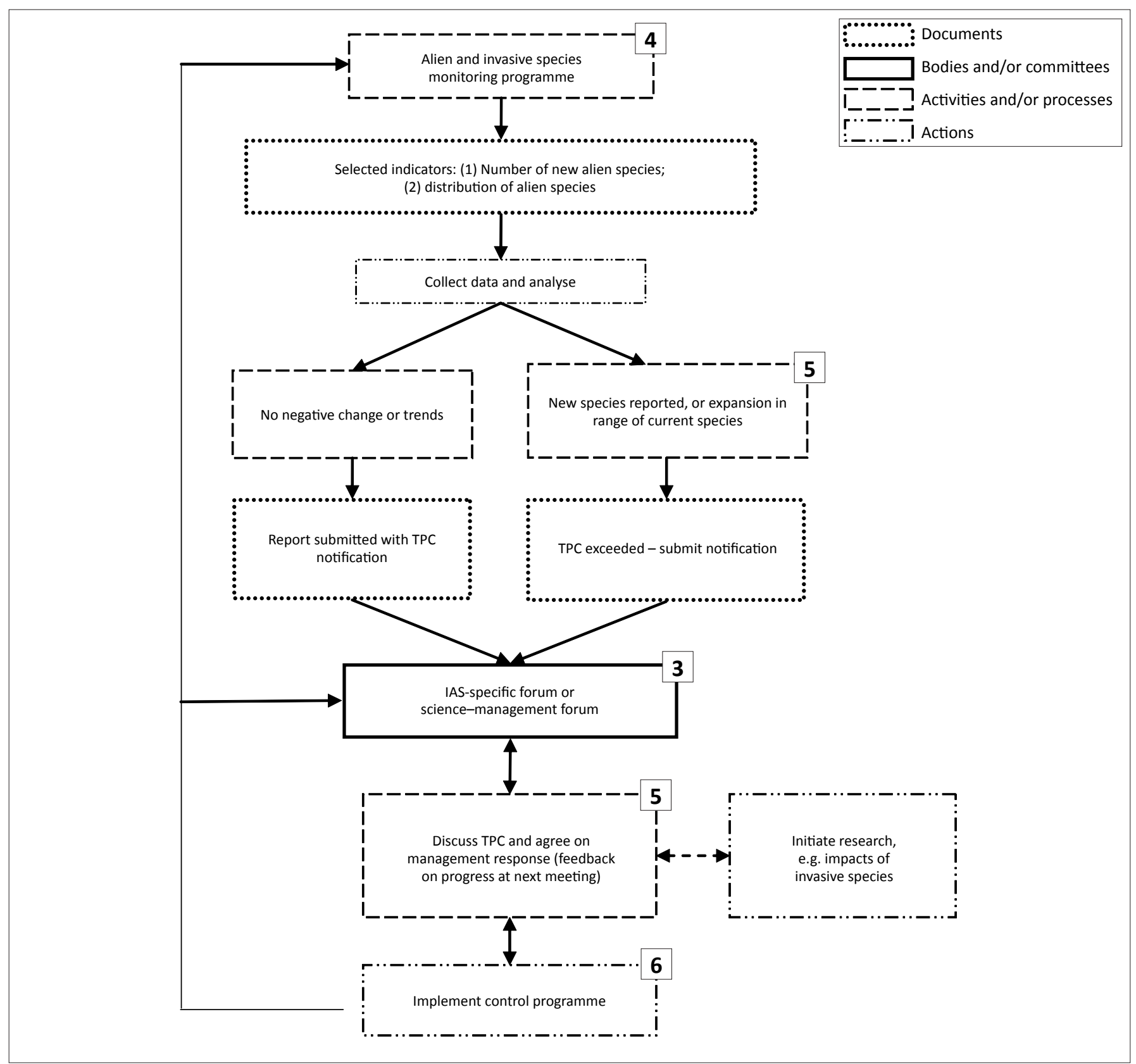

IAS, invasive alien species; TPC, threshold of potential concern.

FIGURE 3: A schematic figure of the monitoring process (as a more detailed subset of Figure 2). The aim of the monitoring programme is to detect the change and trends in the number and distribution of alien species in a predefined area.

Despite a number of barriers (see Jacobson et al. 2006) that will require ongoing assessment and reflection, the framework provides one approach for fully implementing AM. In future, options should be explored for streamlining and simplifying the array of documents, bodies and/or committees and processes that constitute invasive alien species management (as reflected in the supplementary material, Figure 1).

The framework for invasive alien species management presented here formally links and establishes the relationships between various existing and some new management functions. Implementation of such a framework, supported by a clearer governance structure, will better enable effective alien species management via improved flexibility of management operations and the speed at which management actions take place. It will also allow for the assessment of environmental effectiveness and management costs (Hall \& Fleishman 2009). In the context of managing invasive alien species, SAM should assist with integrating project management, park management and monitoring of invasive alien species and include more effective feedback mechanisms. We therefore suggest that the proposed framework provides a simple yet robust way of organising and connecting the various facets of invasive species management in SANParks.

\section{Acknowledgements}

L.C.F. and M.M. thank the DST-NRF Centre of Excellence in Invasion Biology, Stellenbosch University for funding 
and support. This work was supported financially by the National Research Foundation, with grants to both L.C.F. and M.M. We thank two anonymous reviewers for their valuable insights and comments.

\section{References}

Bestbier, R.X., Jacoby, D.L. \& Rogers, K.H., 2000, A goal maintenance system for the management of the Kruger National Park riverine alien vegetation: developing a protocol and a prototype, Water Research Commission, Pretoria.

Biggs, H.C. \& Rogers, K.H., 2003, 'An adaptive system to link science, monitoring, and management in practice', in J.T. du Toit, K.H. Rogers \& H.C. Biggs (eds.), The Kruger Experience: ecology and management of savanna heterogeneity, pp. 59-80, Island Press, Washington DC.

Buckley, R., Robinson, J., Carmody, J. \& King, N., 2008, 'Monitoring for management of conservation and recreation in Australian protected areas', Biodiversity and Conservation 17, 3589-3606. doi:10.1007/s10531-008-9448-7

Cook, D.C., Liu, S., Murphy, B. \& Lonsdale, W.M., 2010, 'Adaptive approaches to biosecurity governance', Risk Analysis 3(9), 1303-1314. doi:10.1111/j.15396924.2010.01439.x

Cowling, R.M., Pressey, R.L., Rouget, M. \& Lombard, A.T., 2003, 'A conservation plan for a global biodiversity hotspot: the Cape Floristic Region, South Africa', Biological Conservation 112(1-2), 191-216. doi:10.1016/S0006-3207(02)00425-1

Crooks, J.A., 2005, 'Lag time and exotic species: The ecology and management of biological invasions in slow-motion', Ecoscience 12(3), 316-329. doi:10.2980/ i1195-6860-12-3-316.1

Dewey, S.A. \& Anderson, K.A., 2004, 'Distinct roles of surveys, inventories, and monitoring in adaptive weed management', Weed Technology 18, 1449-1452. doi:10.1614/0890-037X(2004)018[1449:DROSIA]2.0.CO;2

Elzinga, C.L., Salzer, D.W., Willoughby, J.W. \& Gibbs, J.P., 2001, Monitoring plant and animal populations, Blackwell Science, London.

Folke, C., Hahn, T., Olsson, P. \& Norberg, J., 2005, 'Adaptive governance of socialecological systems', Annual Review of Environment and Resources 30, 441-473. doi:10.1146/annurev.energy.30.050504.144511

Foxcroft, L.C., 2001, 'A case study of the human dimensions in invasion and control of alien plants in the personnel villages of Kruger National Park', in J.A. McNeely (ed.), The Great Reshuffling: human dimensions of invasive alien species, pp. 127-134, IUCN, Gland.

Foxcroft, L.C., 2009, 'Developing thresholds of potential concern for invasive alien species: hypotheses and concepts', Koedoe, 50(1), 6.

Foxcroft, L.C. \& Downey, P.O., 2008, 'Protecting biodiversity by managing alien plants in national parks: perspectives from South Africa and Australia', in B. TokarskaGuzik, J.H. Brock, G. Brundu, L. Child, C.C. Daehler \& P. Pyšek (eds.), Plant invasions: human perception, ecological impacts and management, pp. 387-403, invasions: human perception,
Backhuys Publishers, Leiden.

Foxcroft, L.C. \& Freitag-Ronaldson, S., 2007, 'Seven decades of institutional learning: managing alien plant invasions in the Kruger National Park, South Africa', Oryx 41(2), 160-167. doi:10.1017/\$0030605307001871

Foxcroft, L.C. \& Richardson, D.M., 2003, 'Managing alien plant invasions in the Kruger National Park, South Africa', in L. Child, J. Brock, G. Brundu, K. Prach, P. Pyšek, P. Wade, et al. (eds.), Plant invasions: ecological threats and management solutions, pp. 385-403, Backhuys Publishers, Leiden.

Foxcroft, L.C., Henderson, L., Nichols, G.R. \& Martin, B.W., 2003, 'A revised list of alien plants for the Kruger National Park', Koedoe 46(2), 21-44.

Foxcroft, L.C., Richardson, D.M., Rouget, M. \& MacFadyen, S., 2009, 'Patterns of alien plant distribution at multiple spatial scales in a large national park: implications for ecology, management and monitoring', Diversity and Distributions 15, 367378. doi:10.1111/j.1472-4642.2008.00544.x

Freitag-Ronaldson, S. \& Foxcroft, L.C., 2003, 'Anthropogenic influences at the ecosystem level', in J.T. du Toit, K.H. Rogers \& H.C. Biggs (eds.), The Kruger experience: ecology and management of savanna heterogeneity, pp. 391-421, Island Press, Washington DC.

Gregory, R., Ohlson, D. \& Arvai, J., 2006, 'Deconstructing adaptive management: criteria for applications to environmental management', Ecological Applications,
16(6), 2411-2425. doi:10.1890/1051-0761(2006)016[2411:DAMCFA]2.0.CO;2

Hall, J.A. \& Fleishman, E., 2009, 'Demonstration as a means to translate conservation science into practice', Conservation Biology 24, 120-127. doi:10.1111/j.15231739.2009.01297.x

He, F. \& Gaston, K.J., 2000, 'Occupancy-abundance relationships and sampling scales', Ecography 23, 503-511. doi:10.1034/j.1600-0587.2000.230412.x

Hobbs, R.J. \& Huenneke, L.F., 1992, 'Disturbance, diversity, and invasion: implications for conservation', Conservation Biology 6(3), 324-337. doi:10.1046/j.15231739.1992.06030324.x

Jacobson, S.K., Morris, J.K., Sanders, J.S., Wiley, E.N., Brooks, M., Bennetts, R.E., et al., 2006, 'Understanding barriers to implementation of an adaptive land management program', Conservation Biology 20, 1516-1527. doi:10.1111/j.15231739.2006.00476.x

Kareiva, P., Watts, S., McDonald, R. \& Boucher, T., 2007, 'Domesticated nature: shaping landscapes and ecosystems for human welfare', 'Science 316, 1866-1869. doi:10.1126/science.1140170
Keller, R.P. \& Lodge, D.M., 2010, 'Prevention: Designing and implementing national policy and management programs to reduce the risks from invasive species', in C. Perrings, H.A. Mooney \& M. Williamson (eds.), Bioinvasions and globalization, ecology, economics, management and policy, pp. 220-234, Oxford University ecolog
Press,

Maris, V. \& Béchet, A., 2010, 'From adaptive management to adjustive management: A pragmatic account of biodiversity values', Conservation Biology 24(4), 966-973.

McGeoch, M.A., Dopolo, M., Novellie, P., Hendriks, H., Freitag-Ronaldson, S., Ferreira, S., et al., 2011, 'A strategic framework for biodiversity monitoring in SANParks', Koedoe 53(2), Art. \#991, 10 pages. doi:10.4102/koedoe.v53i2.991

MEA. See Millenium Ecosystem Assessment.

Millennium Ecosystem Assessment, 2005, Ecosystems and human well-being: current state and trends, Island Press, Washington DC.

Pickett, S.T.A. \& Thompson, J.N., 1978, 'Patch dynamics and the design of nature reserves', Biological Conservation 13, 27-37. doi:10.1016/0006-3207(78)90016-2

Pickett, S.T.A., Cadenasso, M.L. \& Benning, T.L., 2003, 'Biotic and abiotic variability as key determinants of savanna heterogeneity at multiple spatiotemporal scales', in J.T. du Toit, K.H. Rogers \& H.C. Biggs (eds.), The Kruger experience: ecology and management of savanna heterogeneity', pp. 22-40, Island Press, Washington DC.

Pickett, S.T.A., Kolasa, J. \& Jones, C.G., 2007, Ecological understanding: the nature of theory and the theory of nature, 2 nd edn., Academic Press, San Diego.

Pyšek, P. \& Richardson, D.M., 2010, 'Invasive species, environmental change and management, and health', Annual Review of Environment and Resources 35, 1-31.

Pyšek, P., Richardson, D.M., Rejmánek, M., Webster, G.L., Williamson, M. \& Kirschner, J., 2004, 'Alien plants in checklists and floras: towards better communication between taxonomists and ecologists', Taxon 53(1), 131-143.

Rejmánek, M. \& Pitcairn, M.J., 2002, 'When is eradication of exotic pest plants a realistic goal?', in C.R. Veitch \& M.N. Clout (eds.), Turning the tide: the eradication of invasive species, pp. 249-253, IUCN, Gland.

Richardson, D.M., Bond, W.J., Dean, W.R.J., Higgins, S.I., Midgley, G.F., Milton, S.J., et al., 2000, 'Invasive alien organisms and global change: A South African perspective' in H.A. Mooney \& H.A. Hobbs (eds.), Invasive species in a changing world, pp. 303-349, Island Press, Washington DC.

Richardson, D.M., Rouget, M. \& Rejmánek, M., 2004, 'Using natural experiments in the study of alien tree invasions: opportunities and limitations', in M.S. Gordon \& S.M. Bartol (eds.), Experimental approaches to conservation biology, pp. 180-201, University of California Press, Berkeley.

Rogers, K.H., 2003, 'Adopting a heterogeneity paradigm: implications for management of protected savannas', in J.T. du Toit, K.H. Rogers \& H.C. Biggs (eds.), The Kruger experience: ecology and management of savanna heterogeneity, pp. 41-58, Island Press, Washington DC.

Roux, D.J. \& Foxcroft, L.C., 2011, 'The development and application of strategic adaptive management within South African National Parks', Koedoe 53(2), Art. \#1049, 5 pages. doi:10.4102/koedoe.v53i2.1049

Salafsky, N., Margoluis, R. \& Redford, K.H., 2001, Adaptive management: a tool for conservation practitioners, Biodiversity Support Programme, Washington DC.

Salafsky, N., Margoluis, R., Redford, K.H. \& Robinson, J.G., 2002, 'Improving the practice of conservation: a conceptual framework and research agenda for conservation science', Conservation Biology 16(6), 1469-1479. doi:10.1046/ j.1523-1739.2002.01232.x

Scholes, R.J. \& Kruger, J.M., 2011, 'Triggers for management intervention in uncertain, varying and time-lagged ecosystems', Koedoe 53(2), Art. \#987, 8 pages. doi:10.4102/koedoe.v53i2.987

South African National Parks, 2006, 'Mapungubwe National Park: Park Management Plan', Unpublished management plan, South African National Parks, Pretoria.

Stafford-Smith, D.M., Abel, N., Walker, B.H. \& Chapin III, F.S., 2009, 'Drylands: Coping with uncertainty, thresholds and changes in state', in F.S. Chapin III, G.P. Kofinas \& D. Folke (eds.), Principles of ecosystem stewardship: resilience-based natural resource management in a changing world, pp. 171-195, Springer, New York.

Stem, C., Margoluis, R., Salafsky, N. \& Brown, M., 2005, 'Monitoring and evaluation in conservation: a review of trends and approaches', Conservation Biology 19, in conservation: a review of trends and approache
295-309. doi:10.1111/j.1523-1739.2005.00594.x

Timko, J.A. \& Innes, J.L., 2009, 'Evaluating ecological integrity in national parks: Case studies from Canada and South Africa', Biological Conservation 142, 676-688. doi:10.1016/j.biocon.2008.11.022

Tu, M., 2009, 'Assessing and managing invasive species within protected areas' in J. Ervin (ed.), Protected area quick guide series, pp. 1-40, The Nature Conservancy, Arlington, VA

Van Wilgen, B.W., Khan, A. \& Marais, C., 2011, 'Changing perspectives on managing biological invasions: insights from South Africa and the Working for Water Programme', in D.M. Richardson (ed.), Fifty years of invasion ecology: the legacy of Charles Elton, pp. 373-393, Blackwell Publishing, Oxford.

Van Wilgen, B.W., Le Maitre, D.C. \& Cowling, R.M., 1998, 'Ecosystem services, efficiency, sustainability and equity: South Africa's Working for Water programme',
Trends in Ecology and Evolution 13, 378. doi:10.1016/S0169-5347(98)01434-7

Venter, F.J., Naiman, R.J., Biggs, H.C. \& Pienaar, D.J., 2008, 'The evolution of conservation management philosophy: science, environmental change and social adjustments in Kruger National Park', Ecosystems 11, 173-192. doi:10.1007/ s10021-007-9116-x

Wittenberg, R. \& Cock, M.J.W. (eds.), 2001, Invasive alien species: a toolkit of best prevention and management practices, $\mathrm{CAB}$ International, Wallingford.

Woodroffe, R. \& Ginsburg, J.R., 1998, 'Edge effects and the extinction of species inside protected areas', Science 280, 2126-2128. doi:10.1126/science.280.5372.2126 


\section{Supplementum}

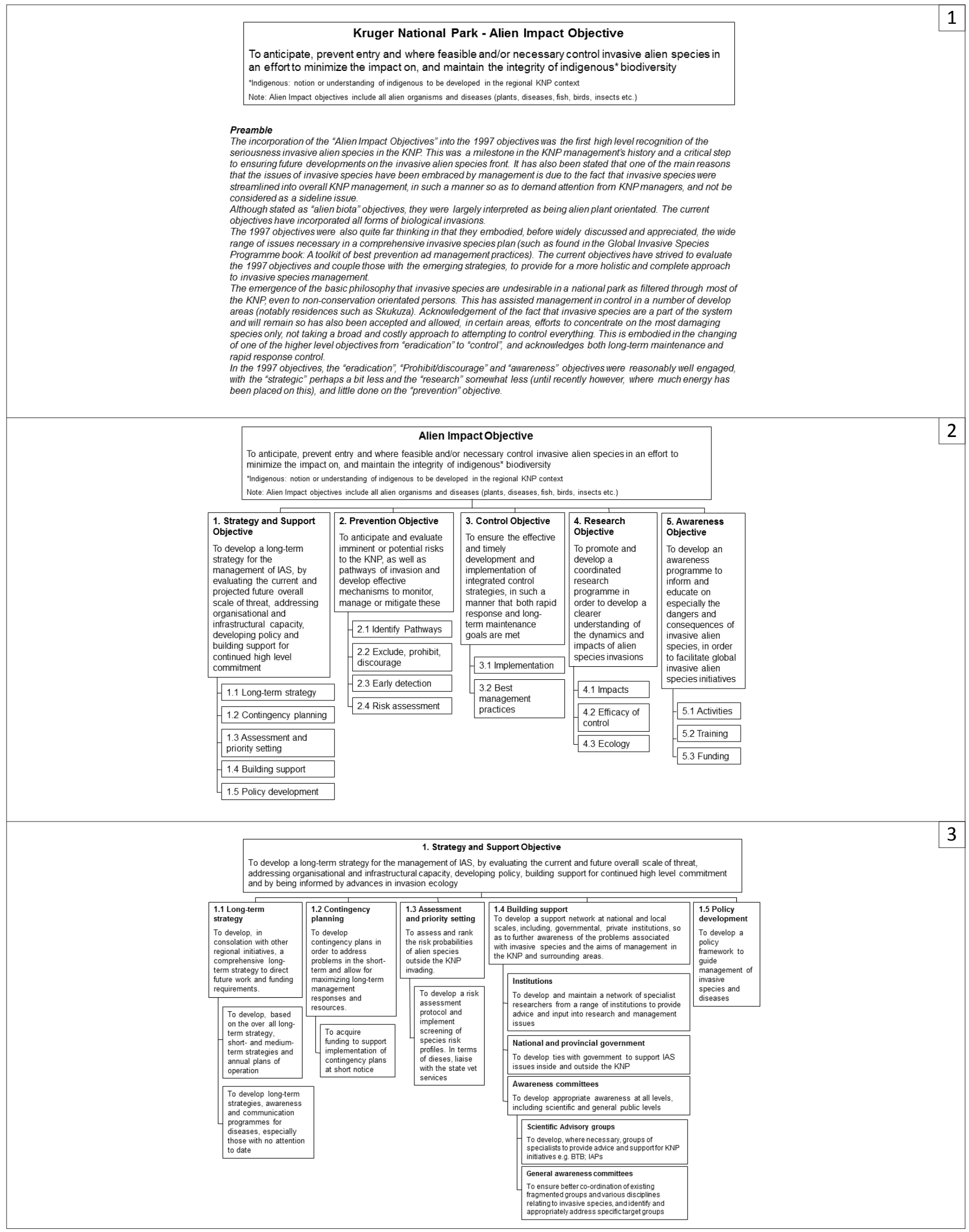

FIGURE 1: An expanded overview of the proposed framework to implementing the control of invasive alien species. The framework indicates the key components, with the salient points, and their linkages. The numbers cross link to the discussion. We also differentiate between documents, activities and/or processes, actions, and bodies and/or committees. 


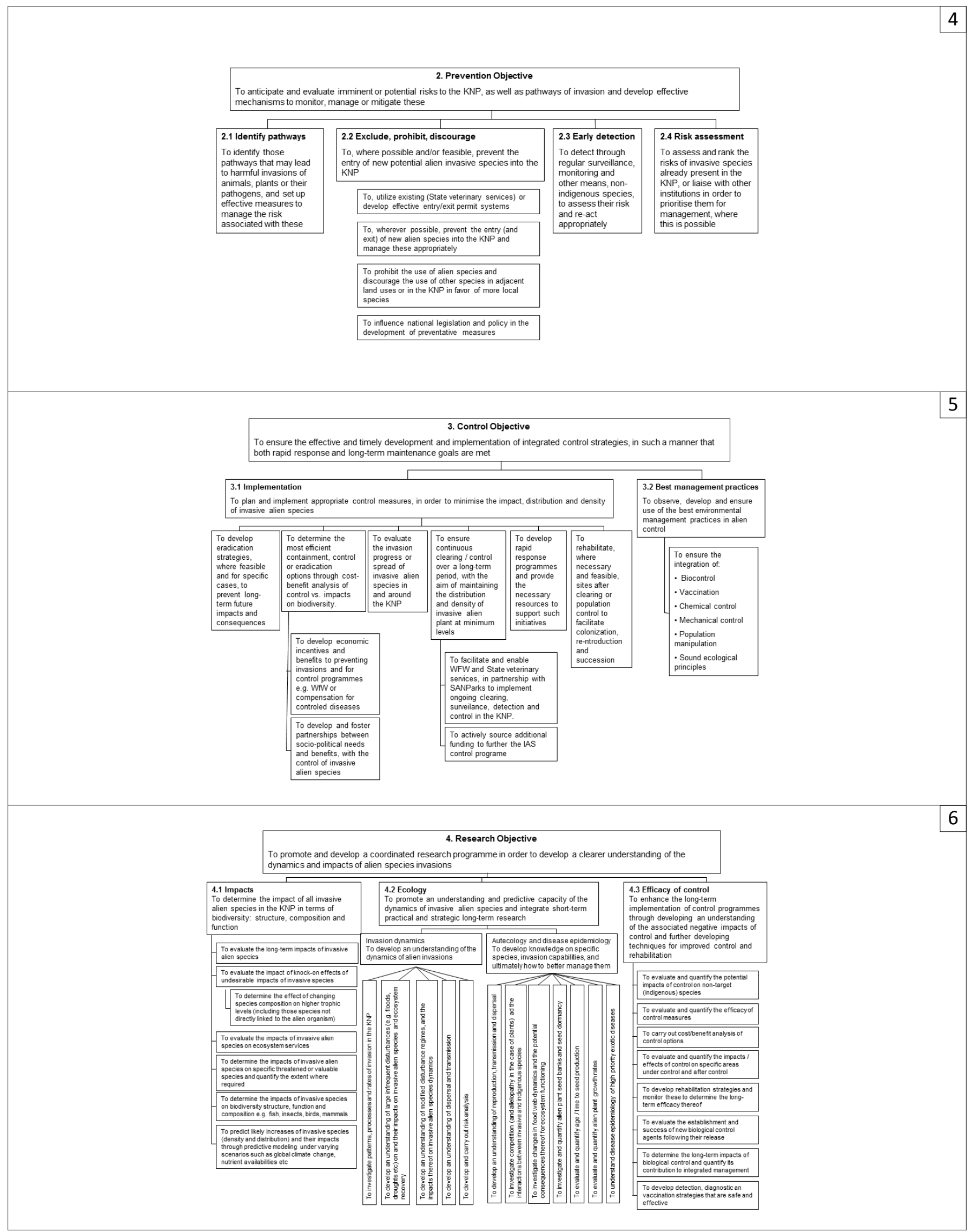

FIGURE 1 (Continues...): An expanded overview of the proposed framework to implementing the control of invasive alien species. The framework indicates the key components, with the salient points, and their linkages. The numbers cross link to the discussion. We also differentiate between documents, activities and/or processes, actions, and bodies and/or committees. 


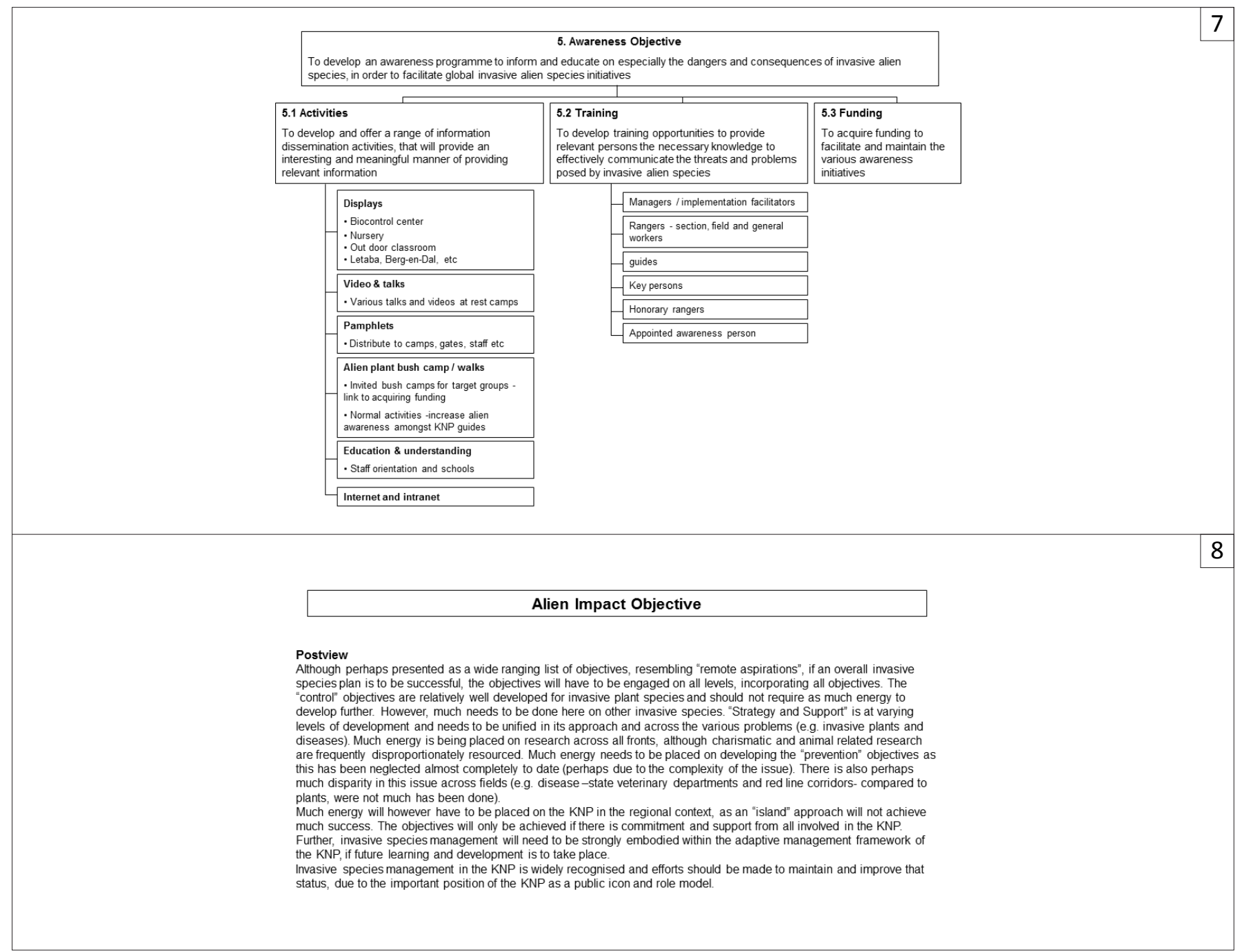

FIGURE 1 (Continues...): An expanded overview of the proposed framework to implementing the control of invasive alien species. The framework indicates the key components, with the salient points, and their linkages. The numbers cross link to the discussion. We also differentiate between documents, activities and/or processes, actions, and bodies and/or committees. 